ENSV TEADUSTE AKADEEMIA TOIMETISED. XVI KOIDE

KEEMIA * GEOLOOGIA. 1967, Nr. 2

ИЗВЕСТИЯ АКАДЕМИИ НАУК ЭСТОНСКОИ ССР. ТОМ XVI

Химия * ГЕОЛОГия. 1967, № 2

В. ОЛЛИ

\title{
О ПРОЦЕССЕ ВЫХОДА ФИЛЬТРАЦИОННОГО ПОТОКА НА ПЕСЧАНЫИ ОТКОС
}

Процесс выхода фильтрационного потока из откоса и связанные с ним явления изучались многими исследователями. М. Аверочкина (1958) выделяет на фильтрующем песчаном откосе три зоны. Из них верхняя является воздушно-сухой или содержит только капиллярную влагу и поэтому наиболее устойчива. Ниже следует зона высачивания воды. Здесь на откос воздействуют как фильтрационное гидродинамическое давление, так и эрозия выделившейся воды. Эта зона нанменее устойчнва. Следующая зона расположена ниже уровня воды. Она более устойчива, так как градиенты здесь невелики.

О величине выходного градиента в средней зоне разные исследователи высказывают различные мнения. М. Цытович (1951) считает, что выходной градиент равен тангенсу угла наклона откоса. По В. Кульбаху *, выходной градиент равен синусу этого угла. М. Аверочкина не связывает выходной градиент с величиной наклона откоса. По ее мнению, выходной градиент можно определить с достаточной точностью путем замера высоты уровня воды в скважине на берегу канавы и высоты верхнего края видимой зоны выхода воды на откос.

Имеется также ряд теоретических и экспериментальных исследований по расчету высоты высачивания воды из откоса в различных условиях, по расчету длины и крутизны оплывшего откоса и о защитной роли гравийных пригрузок на откосах (Шестаков, 1955, 1959 и др.).

Ниже приводятся результаты некоторых наших опытов по изучению процесса выхода грунтового потока из песчаного откоса и связанных с этим процессом явлений. Опыты проводились в небольшом металлическом лотке сечением около $200 \mathrm{~cm}^{2}$ с прозрачной передней стенкой. Для визуального наблюдения и фотографирования линин тока применялся метод окрашивания, предложенный В. Стапренсом (1954). Краска (бромокрезоловый синий) вводилась в фильтрационный поток через мелкие отверстия, проделанные в передней стенке лотка. Исследования провсдились с однородными мелко- и тонкозернистыми четвертичными песками прибрежно-морского происхождения.

Опыты показывают, что, приближаясь к откосу с прямым профилем, линии тока изгибаются плавно вниз и сходятся к урезу воды в нижнем бьефе (рис. 1). К этой же точке устремляется и капиллярная часть потока, скорость которой в нижней части не отличается от скорости движения свободной воды. На урезе воды образуется весьма узкая полоса сконцентрированного высачивания, где и начинается оплывание откоса.

* Куль 6 ах В. Р., Оплывание песчаных откосов под воздействием фильтрационного потока, Ленингр, политехн. ин-т. Дисс. канд. техн. наук, 1955. 


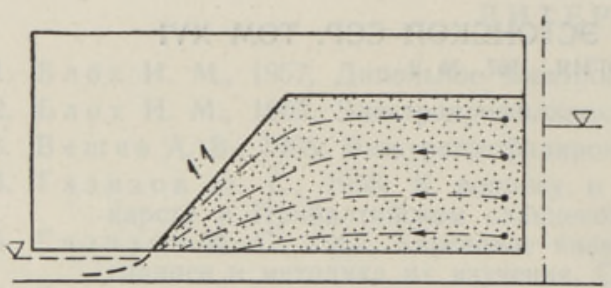

Рис. 1. Линии тока при выходе фильтрационного потока на откос прямого профиля. (Усл. обозн, см. рис. 3).

Ниже уровня воды в нижнем бьефе линии тока выходят из откоса рассредоточенно, перпендикулярно к последнему.

Ширина полосы интенсивного высачивания воды зависит от величины выходного градиента (несколько возрастая с увеличением последнего) и от крутизны откоса. На пологих откосах, при прочих равных условиях, ширина полосы высачивания больше и выход воды менее сконцентрирован, чем на крутых откосах, что в свою очередь обусловливает бо́льшую устойчивость такого откоса против оплывания. Уменьшая крутизну откоса, можно достигнуть такого положения, что вода высачивается рассредоточенно со всей площади откоса и дальнейшее выполаживание последнего фильтрационным потокбм становится невозможным.

Именно такие «предельные» откосы и образуются при оплывании (см. рис. 3, 2). Несмотря на то, что песок в оплывшем откосе находится в разжиженно-плывучем состоянии, рассредоточенное на всю площадь гидродинамическое давление уравновешивается весом песчинок. Дальнейшее выполаживание такого откоса может протекать только путем поверхностной эрозии высачивающейся водой.

Я. Одынь (1957), изучая деформации лесоосушительных канав в Латвии, пришел к выводу, что канавы с вогнутым (параболическим) поперечным сечением более устойчивы, чем канавы с обычным трапецеидальным сечением. Для выяснения причин этого явления нами изучался процесс выхода грунтового потока из откоса вогнутого профиля.

Рис. 2. Линии тока при выходе фильтрационного потока на откос вогнутого профиля. (Усл. обозн. см. рис. 3)

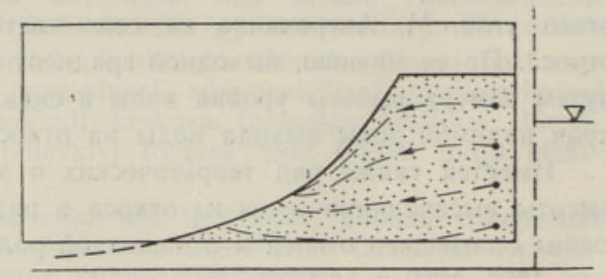

На рис. 2 изображены линии тока, выходящие на вогнутый откос. Қак видно из рисунка, в нижней части откоса, уклон которой меньше уклона оплывшего откоса для данного песка, вода выходит рассредоточенно на относительно широкой полосе. В точке, где уклон откоса начинает превышать уклон оплывания, наблюдается некоторое сосредоточение линий потока. В случае, когда градиент потока превышает критическую величину, оплывание начинается именно с этой "точки. Однако для разрушения прямого откоса требуются значительно меньшие градиенты фильтрационного потока, чем для разрушения вогнутых откосов с таким же средним уклоном.

Из изложенного вытекает, что полного предотвращения оплывания песчаного откоса можно достигнуть в том случае, если удастся рассредоточить фильтрационное гидродинамическое давление на достаточно большую поверхность откоса. Как показывают опыты, эффективное рассредоточение линий тока достигается насыпкой на откос обратного фильтра из более водопроницаемого материала, чем материал самого откоса.

Широко применяемая на практике гравийная засыпка ра̉ссматривается обычно как механическая защитная пригрузка. Под водой это, 

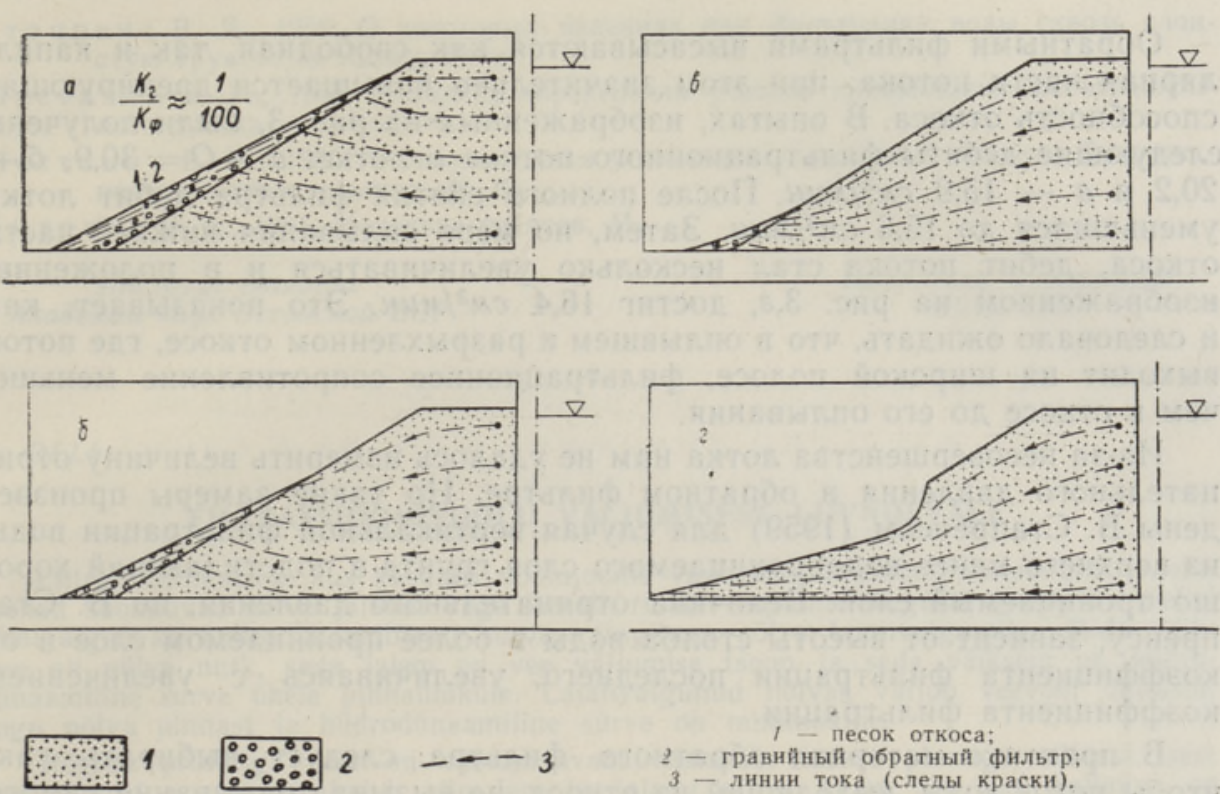

$t$ - песок откоса;

2 - гравнйный обратный фнльтр: 3 - лннин тока (следы краски).

Рис. 3, Линии тока при выходе фнльтрационного потока на откос:

$a$ - откос покрыт обратным фильтром; 6 -- откос покрыт фильтром только наполовину: в - фильтром покрыто только подножие откоса; 2 - фильтрполностью снят, подножие откоса оплыло.

очевидно, так и есть. Однако выше уровня воды в ннжнем бьефе гравийная засыпка приобретает дополнительно некоторые новые свойства.

В. Стапрено (1959) указывает, что насыпка на откос обратного фнльтра соответствующей крупнозернистости создает значительный дополнительный гидравлический градиент. Наши опыты с наблюдением фактических путей движения частиц воды полностью подтверждают это положение.

На рис. 3,a показан путь потока, выходящего из тонкозернистого песчаного откоса, покрытого по всей высоте обратным фильтром. Линии тока, вместо того чтобы опускаться вниз к подножию откоса, даже несколько поднимаются вверх и только после перехода в слой фильтра резко поворачивают вниз. Из фильтра они выходят, как обычно, около уреза воды в нижнем бьефе.

Такое явление объясняется отрицательным давлением, возникающим в слое фильтра. Вода в порах фильтра, обладаюшего относительно высокой водопроницаемостью, притягивается собственным весом вниз. Однако проникновение воздуха в поры предотвращается капиллярными силами. Но так как в месте контакта фильтра с грунтом откоса мениски отсутствуют, то отрицательное давление в фильтре свободно передается воде в порах откоса и последняя постоянно всасывается в фильтр.

На рис. 3,б и в показан тот же откос, но покрытый фильтром соответственно только наполовину и на пятую часть. На этих рисунках лінии тока вначале устремляются вниз, но потом также направляются к фильтру. Затем, когда фильтр был полностью снят с откоса, сразу же начался процесс оплывания. В положении, показанном на рис. 3 ,2, было достигнуто равновесие, причем дальнейшее оплывание откоса прекратилось. 
Обратными фильтрами высасываются как свободная, так и капиллярная части потока; при этом значительно повышается дренирующая способность откоса. В опытах, изображенных на рис. 3, были получены следующие дебиты фильтрационного потока в лотке: $a-Q=30,9, \sigma-$ 20,2 и $в-15,9 \mathrm{~cm}^{3} / \mathrm{Muн}$. После полного снятия фильтра дебит лотка уменьшился до $15,6 \mathrm{~cm}^{3} /$ мин. Затем, по мере оплывания нижней части откоса, дебит потока стал несколько увеличиваться и в положении,

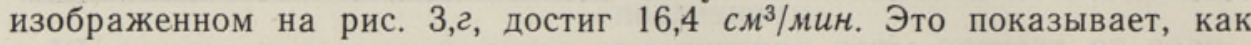
и следовало ожидать, что в оплывшем и разрыхленном откосе, где поток выходит на широкой полосе, фильтрационное сопротивление меньше, чем в откосе до его оплывания.

Из-за несовершенства лотка нам не удалось измерить величину отрицательного давления в обратном фильтре. Но такие замеры произведены В. Стапренсом (1959) для случая вертикальной фильтрации воды из верхнего менее водопроницаемого слоя грунта в подстилающий хорошо проницаемый слой. Величина отрицательного давления, по В. Стапренсу, зависит от высоты столба воды в более проницаемом слое и от коэффициента фильтрации последнего, увеличиваясь с увеличением коэффициента фильтрации.

В практике материал обратного фильтра следует выбирать так, чтобы поток воды, выходящий из откоса, не вызывал оплывания самого слоя фильтра. Опыты в лотке показали, что обратный фильтр может оплывать при

$$
\frac{K_{\phi}}{K_{\mathrm{r}}}<10
$$

где $K_{\phi}$ и $K_{г}-$ коэффициенты фильтрации материала фильтра и грунта откоса соответственно. Следовательно, материал обратного фильтра должен соответствовать условию

$$
\frac{K_{\phi}}{K_{\mathrm{r}}}>15 \div 20
$$

Для предотвращения засорения фильтра контактным размывом (проникновение частиц грунта откоса в фильтр под давлением потока воды) можно пользоваться критерием, предложенным В. Шестаковым (1959), согласно которому

$$
\frac{D_{10}}{d_{50}}<15 \div 20
$$

где $D$ и $d$ - соответственно диаметры частиц обратного фильтра и грунта откоса.

\section{ЛИТЕР А Т Р А}

А в ер о чкина М. В., 1958, Деформация песчаных откосов осушительных каналов, вызванные фнльтрационным давлением, Вестн. МГУ. Сер. биол., почвовед., геол, и геогр., № 2.

О дын ь Я. Я., 1957. Поперечный профиль лесоосушительных каналов в Латвийской ССР, Сб. Исследования по вопросам строительства и эксплуатации осушительных систем, Рига.

С т а п ре н с В. Я., 1954, Миграция капиллярно-связанной влаги в зоне аэрации, Рига. 
С тапренс В. Я., 1959, О некоторых явлениях при фильтрации воды сквозь слоистую грунтовую толщу, Рига.

Ш естаков В. М., 1955, Методика определения участка высасывания фильтрационного потока на откос, $M$.

Ш ест а ко в В. М., 1959, Фильтрационная устойчивость песчаных откосов, Гидротехническое строительство, № 10.

IЦы то в и ч Н. А., 1951, Механика грунтов, М.

Институт геологии

Академии наук Эстонской ССР
Поступила в редакцию 30/IX 1966

\section{V. $O L L I$}

\section{FILTRATSIOONIVOOLU VÄLJUMISEST LIIVNOLVALE}

Filtratsioonikatsed, kus kasutati voolujoonte värvimise meetodit, näitasid, et voolujooned koonduvad nōlva jalamil väga kitsale ribale veepinna kôrgusel (joon. 1). Sellel ribal algab ka hüdrodünaamilisest survest tingituna nõlva laialivalgumine. Mida väiksem on nōlva nurk, seda laiem on vee väljumise tsoon ja seda väiksem on hüdrodünaamiline surve ühele pinnaühikule. Laialivalgunud nōlvas väljub veevool ühtlaselt kogu nōlva pinnast ja hüdrodünaamiline surve on minimaalne.

Nōgusa profiiliga nōlv on vastupidavam vastavast tasase pinnaga nōlvast, sest osa alumisi voolujooni hajub siin lameda jalami piires (joon. 2), kus kallakus on văiksem laialivalgunud nōlva kallakusest. Qlejäänud voolujooned aga koonduvad ühte punkti kohas, kus kallakus ületab kriitilise väärtuse. Sellest punktist algab küllalt suure voolugradiendi puhul ka nõlva lagunemine.

Nõlvale asetatud jämedamast materjalist (kruusast) pöördfilter imeb temas tekkiva negatiivse surve tõttu nōlvast vett ja voolujooned jaotuvad seetōttu kogu filtriga kaetud nôlvaosale (joon. $3, a, \sigma, \theta$ ). See vähendab hüdrodünaamilist survet ühele pinnaühikule niivõrd, et nōlva laialivalgumine on välditud.

Pöördfilter nōlval suurendab tunduvalt ka nōlva dreenivat toimet.

\section{OLLI}

\section{ON THE DISCHARGE OF THE FILTRATIONAL FLOW ON A SANDY SLOPE}

Filtration tests, in which the method of tinting the flow lines was applied, showed that the flow lines concentrate at the foot of the slope, on a very narrow stripe at water-level (fig. 1). The destruction of the slope, caused by hydrodynamical pressure, starts on this stripe as well. The smaller the angle of the slope, the wider the zone of the discharge of water, and the smaller the hydrodynamical pressure upon a surface unit. The flow of water in a destroyed slope is discharged equally from the surface of the entire slope, and the hydrodynamical pressure is minimal.

The slope with a concave profile is stabler than the level slope since a part of the lower flow lines is dispersed within the limits of flat foot of the slope (fig. 2), where the gradient is smaller than that of a destroyed slope. The rest of the flow lines, however, concentrate in a point where the gradient exceeds the critical value. In that point, in case of a considerable flow-gradient, the destruction of the slope begins to be effected.

A filter made of coarse-grained material (gravel) sucks the water out of the slope, owing to the negative pressure formed in it, and the flow lines are, therefore, distributed over the whole part of the slope that is covered by the filter (fig. 3, $a, \sigma, \boldsymbol{b})$. This decreases the hydrodynamical pressure falling upon a surface unit to such an extent that the washing-out of the slope is avoided. the slope

The filter placed on the slope simultaneously increases the draining effect of 